\title{
Pattern of wing moult and its relationship to breeding in the Eurasian Stone-curlew Burhinus oedicnemus
}

\author{
Dimitri Giunchi $^{1{ }^{1 *}}$, Chiara Caccamo ${ }^{1}$ \& Enrica Pollonara ${ }^{1}$
}

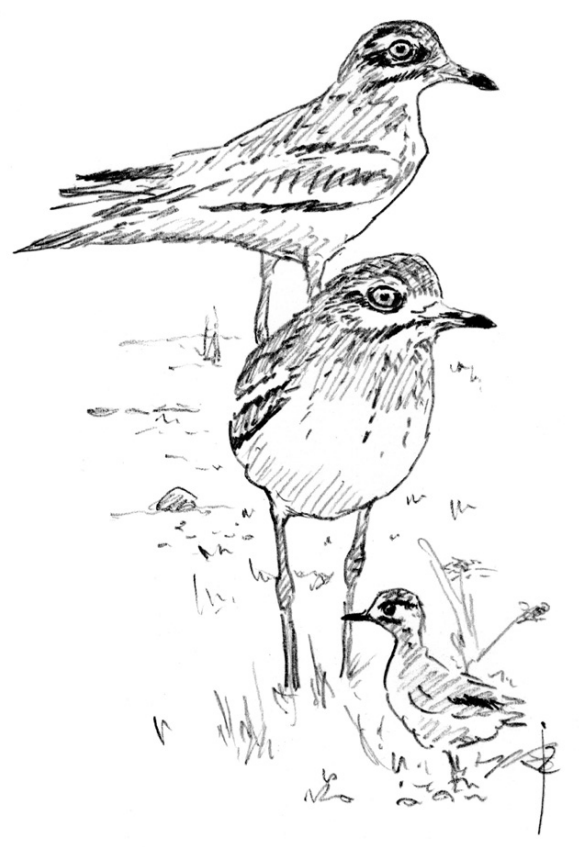

Giunchi D., Caccamo C. \& Pollonara E. 2008. Pattern of wing moult and its relationship to breeding in the Eurasian Stone-curlew Burhinus oedicnemus. Ardea 96(2): 251-260.

The timing, duration and pattern of the poorly documented wing moult in the Eurasian Stone-curlew Burhinus oedicnemus were described and related to the breeding cycle. Between 1998 and 2007, 141 birds were trapped in the Taro River Regional Park (Parma, Italy) both while incubating and during the post-breeding season. The timing of primary moult was estimated according to the method of Underhill \& Zucchini (1988) and Underhill et al. (1990). Primary moult was very slow and overlapped most of the breeding season, beginning in early May and ending in October. Secondary moult was much more irregular and was not completed within a single moult cycle. Innermost and outermost secondaries were more likely to be shed than those at the centre of this tract. Juvenile secondaries were not shed during the first winter. The study provides the first detailed analysis of wing moult in the Eurasian Stone-curlew and suggests some useful ageing criteria based on the pattern of secondary moult. The extensive overlap between breeding and moulting is relatively uncommon compared to other waders. This could be interpreted as a way to maximize breeding success through renesting potential (up to 4 attempts), i.e. by spreading the cost of moult over a prolonged time period. A between-species comparison using independent contrasts was consistent with this hypothesis: species with a prolonged breeding season also showed considerable overlap in the timing of primary moult and breeding activities.

Key words: Eurasian Stone-curlew, Burhinus oedicnemus, wing moult, moult-breeding overlap, ageing criterias

${ }^{1}$ Dipartimento di Biologia, Università di Pisa, Via Volta 6, I-56126, Pisa, Italy;

*corresponding author (dgiunchi@biologia.unipi.it)

\section{INTRODUCTION}

Moult in waders (Charadriiformes) has been generally investigated in depth for many species (e.g. Holmgren et al. 2001, Summers et al. 2004, Serra et al. 2006), but that of the Eurasian Stone-curlew Burhinus oedicnemus (hereafter Stone-curlew) remains poorly known. Indeed, current descriptions regarding this bird (Cramp \& Simmons 1983, Ginn
\& Melville 1983) are based on small sample sizes, and they are not easily comparable to that of other species because they were made well before the latest statistical methodology designed for the analysis of moult data became available (Underhill \& Zucchini 1988, Underhill et al. 1990). Furthermore, no information regarding the pattern of secondary moult is currently available, nor did these earlier studies report additional information that 
enables the moult to be reliably placed within the context of the species' annual cycle. This seems to be a particularly significant omission, because in this species the data at hand suggest a large overlap between breeding and moult (Cramp \& Simmons 1983), which is relatively rare for birds in temperate areas, where seasons are marked and predictable (Jenni \& Winkler 1994, Moreno 2004). Given that relatively few studies have investigated the costs and benefits of this overlap, and consequently the reasons for its higher frequency in tropical rather than in temperate species are poorly understood (Foster 1974, Jenni \& Winkler 1994, Moreno 2004), it seems likely that an indepth investigation of the moult strategy of the Stone-curlew could provide important information on this topic. The aim of this paper is to examine the timing, duration and pattern of wing moult in the Stone-curlew and to relate these parameters to the breeding cycle of the study population.

\section{METHODS}

Our study was performed during 1998-2007 in the Taro River Regional Park (Parma, Italy; $44.74^{\circ} \mathrm{N}, 10.17^{\circ} \mathrm{E}$; total area $25 \mathrm{~km}^{2}$ ), which hosts a relatively large breeding population of Stonecurlews (more than 80 pairs, Pollonara et al. 2001), mainly nesting along the dry gravel riverbed. 141 birds were caught either while incubating, using a fall trap over the nest (April-July, $\mathrm{n}=$ 101 ), or in the post-breeding season, using mistnets placed near late summer-autumn roosts (August-November, $n=40$ ). For 21 birds which were trapped more than once the first retrap within each year was considered as a first capture and thus included in the analysis. This gave a total of 166 records, 119 for the breeding season and 47 for the post-breeding season. All the considered birds were at least in their second calendar-year. Juvenile birds trapped in the post-breeding season, as recognized by their plumage characteristics (see Prater et al. 1977), were excluded from the analysis. In this regard it should be noted that post-juvenile moult of Stone-curlew is a 'partial moult', involving only body feathers, some rectrices and some great coverts, while post-breeding moult is usually described as a 'complete moult' (Ginn \& Melville 1983).

The stage of the moult of the remiges was described using the British Trust for Ornithology method (Ginn \& Melville 1983) by allocating a score to each feather according to its state of growth $(0=$ old feather; $1=$ feather in pin; $2=$ brush to one-third grown; $3=$ one-third to twothirds grown; $4=$ two-thirds to fully grown; $5=$ new feather). For the purpose of the analysis the 10 innermost primaries (the vestigial eleventh was ignored), numbered from innermost to outermost, and the 12 outermost secondaries, numbered from outermost to innermost were considered. The timing and duration of moult was rigorously described only for the primaries, because they were completely replaced within one moult cycle (Cramp \& Simmons 1983, Ginn \& Melville 1983). Primary feather scores were converted to percentage mass grown using the percentage mass of each primary derived from Dawson (2005) and reported in Table 1 and the corresponding proportion of feather grown reported in Underhill \& Zucchini (1988). The timing of primary moult was estimated according to the method of Underhill \& Zucchini (1988) and Underhill et al. (1990). We restricted our analysis only to birds not yet

Table 1. Percentage mass of each primary feather in the Eurasian Stone-curlew derived from Dawson (2005, Figure 1).

\begin{tabular}{cc}
\hline Primary feather & \% mass \\
\hline 1 & 4.5 \\
2 & 5.0 \\
3 & 6.0 \\
4 & 7.3 \\
5 & 8.9 \\
6 & 11.0 \\
7 & 12.6 \\
8 & 14.2 \\
9 & 15.1 \\
10 & 15.4 \\
\hline
\end{tabular}


moulted or in moult (data type 5 of Underhill et al. 1990). We assumed that Stone-curlews moulting in our study area arrive with old primaries, but migrate away from this area soon after they have completed moult. This assumption is supported by the following two considerations. 1) Stone-curlews are recorded in our area from the beginning of February, well before the birds commence moult (Giunchi et al. pers. observ.). 2) The number of Stone-curlews recorded in the study area consistently decreased from the beginning of October, just when the moult cycle is completed or nearly completed (see below).

Because we lack data regarding secondary mass, the timing of secondary moult was described using moult scores. In order to speed-up the ringing procedures during incubation we did not record a secondary moult score for all birds (98 records were obtained for 89 individual birds).

By means of linear regression models we tested if the progress of secondary moult (sum of secondary moult scores) was affected by estimated onset date of primary moult, as expected, and by body mass ( $\pm 1 \mathrm{~g}$ ). Estimated onset dates $O D$ were calculated as described in Newton \& Rothery (2005): $O D=t-T \times P F M G$, where $t=$ capture date (days), $T=$ mean moult duration (days), and $P F M G=$ percentage of primary feather mass grown. In all models, capture date was used as covariate. In order to meet the assumptions of linear models (normality and homoscedasticity) the dependent variable was transformed using the Box-Cox transformation (Sokal \& Rohlf 1995). To select the model of maximal parsimony we used Akaike's Information Criterion corrected for small sample size (Burnham \& Anderson 2002). All statistical analyses were performed using software $R$ 2.6.0 (R Development Core Team 2007)

\section{RESULTS}

The parameters of primary moult estimated according to the Underhill-Zucchini model are given in Fig. 1. On the whole the fit of the model appears quite good, and most of the moult index

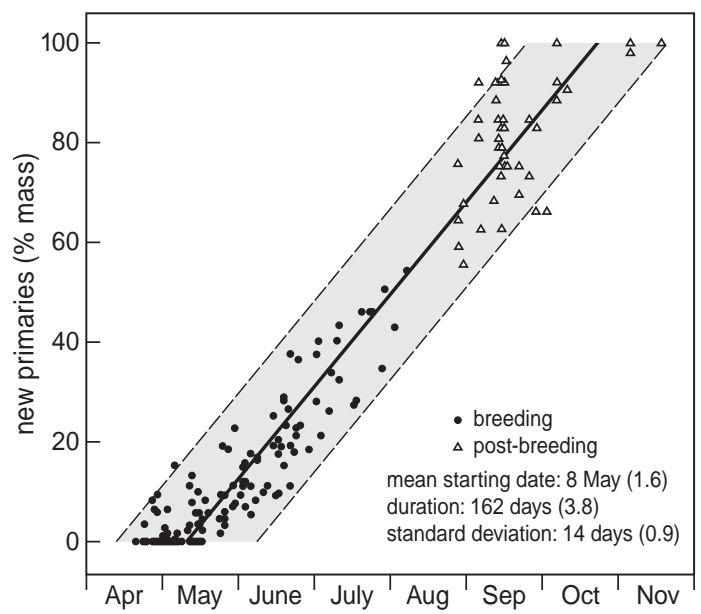

Figure 1. Relationship between the stage of primary moult and date. The solid line shows the mean rate of increase for the average bird, dashed lines are the 95\% confidence intervals. Primary moult parameters are given with standard errors in parentheses.

values fall within the expected range of variation. As assumed by the Underhill-Zucchini model, the estimated onset dates (see Methods) did not show any obvious departure from the normal distribution (Shapiro-Wilk normality test, $W=0.995, P=$ 0.93). On average, primary moult started on 8 May and lasted more than five months, ending on 17 October. More than half of the moult process took place during the breeding season. Primaries were shed sequentially at a quite constant rate, except during the very beginning and the very end of the moult cycle (Fig. 2A). Usually only two, or sometimes three, feathers were growing at the same time during the whole process.

Although some secondaries were replaced as early as at the end of May, i.e. less than one month after the beginning of primary moult, most secondaries were shed during the post-breeding period (Fig. 3). After controlling for capture date, the best predictor of the progress of secondary moult was the estimated onset date of primary moult, as expected (Table 2). The relationship between these two variables was negative (model coefficient was -0.015 , SE $0.004, P<0.001$ ), thus indicating that 

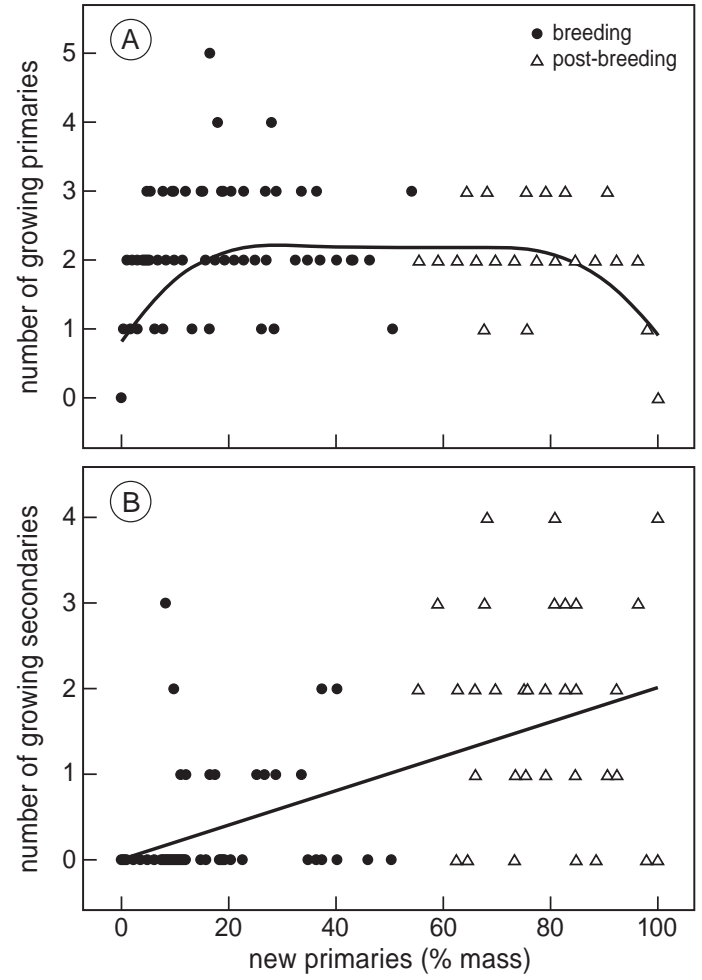

Figure 2. Relationship between the stage of primary moult and numbers of primary (A) and secondary (B) feathers growing simultaneously. Smoothing was calculated by means of a Gaussian kernel estimator and cross-validated choice of bandwidth (Bowman \& Azzalini 1997).

birds starting primary moult earlier tended to show a higher percentage of moulted secondaries, even though the recorded variability was quite high. On the other hand, body mass did not seem to have any effect.

It should be noted that up to c. $80 \%$ of secondaries were replaced during the study period, thus indicating that the post-breeding moult of this population was incomplete. Indeed, most birds (55 out of 63 examined individuals, or $87.3 \%$ ) trapped early in the breeding season (April-May) showed at least two different generations of feathers, the newest secondaries seemingly moulted at the same cycle of primaries, while older ones probably retained from the previous moult cycle.

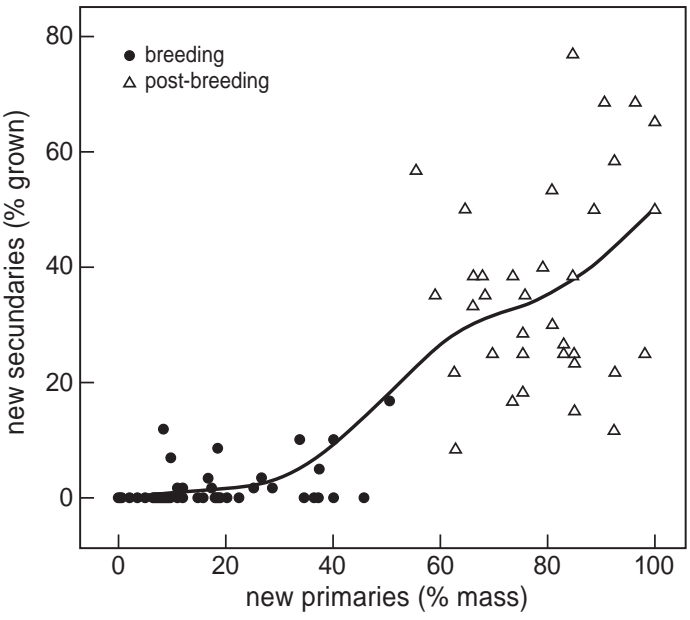

Figure 3. Relationship between the stage of primary moult and secondary moult. Smoothing as in Fig. 2.

Table 2. Analysis of the progress of secondary moult (feather score) using linear regression models evaluated using Akaike's Information Criterion for small sample sizes $\left(\mathrm{AIC}_{c}\right) \cdot k=$ number of parameters. $\Delta \mathrm{AIC}_{c}=$ difference in $\mathrm{AIC}_{c}$ between a given model and the model with the lowest $\mathrm{AIC}_{c} \cdot w_{i} \mathrm{AIC}_{c}=\mathrm{AIC}$ weights, which estimates the probability a specified model is the true model, given that one of the models being considered is indeed the true model.

\begin{tabular}{lcrc}
\hline Model $^{\mathrm{a}}$ & $k$ & $\Delta \mathrm{AIC}_{c}$ & $w_{i} \mathrm{AIC}_{c}$ \\
\hline Capture + Onset $^{\mathrm{b}}$ & 4 & 0.00 & 0.71 \\
Capture + Onset + Mass & 5 & 1.80 & 0.29 \\
Capture & 3 & 11.52 & 0.00 \\
Capture + Mass & 4 & 12.76 & 0.00
\end{tabular}

${ }^{\mathrm{a}}$ Capture: capture date. Onset: estimated onset date of primary moult (see Methods). Mass: body mass at capture.

${ }^{\mathrm{b}} \mathrm{AIC}_{c}=164.4$, residual $\mathrm{SE}=0.56$, adjusted $R^{2}=0.81, P<0.001$.

It is interesting to note that among those individuals that could be precisely aged by means of colour-ringing, all birds with at least two generations of secondaries were at least in their third calendar-year, while no second-calendar birds showed any detectable lack of homogeneity within the secondary tract (Table 3). This highly significant 
Table 3. Number of generations recorded in the secondary tract in relation to the age of birds captured while incubating (Fisher's Exact Test, $P<0.001$ ).

\begin{tabular}{lcc}
\hline \multirow{2}{*}{ Age } & \multicolumn{2}{c}{ No. of generations } \\
& 1 & $2+$ \\
\hline second calendar-year & 3 & 0 \\
$>$ second calendar-year & 0 & 17 \\
\hline
\end{tabular}

association suggested that juvenile secondaries were not shed during the first winter. According to our data second-calendar birds could be identified by the age pattern of secondary feathers and/or by the presence of juvenile secondaries, which are usually narrower and more pointed than adult ones. Moreover, juvenile primaries (especially the tip of the 2-3 outer ones) of these birds are rather pointed, paler and much more worn than secondaries.

As observed for primaries, the moult rate of secondaries was quite slow, and usually no more than three secondaries were growing simultaneously (Fig. 2B). The moult sequence of secondaries was much more irregular than that of primaries. However, the percentage of birds with new or growing feathers in each position clearly indicated that innermost and outermost secondaries were shed more often than feathers belonging to the centre of this feather tract (Fig. 4).

\section{DISCUSSION}

As mentioned in the Introduction, this paper represents the first detailed description of the wing moult of the Stone-curlew, and thus it helps to fill a significant gap in the information regarding the biology of this species. Concerning primary moult, the fit of the Underhill-Zucchini model turned out to be quite good, and parameters were estimated with an acceptable precision, even though the sample size was only moderately large. While significant differences in the timing of wing moult among populations should be expected, as reported

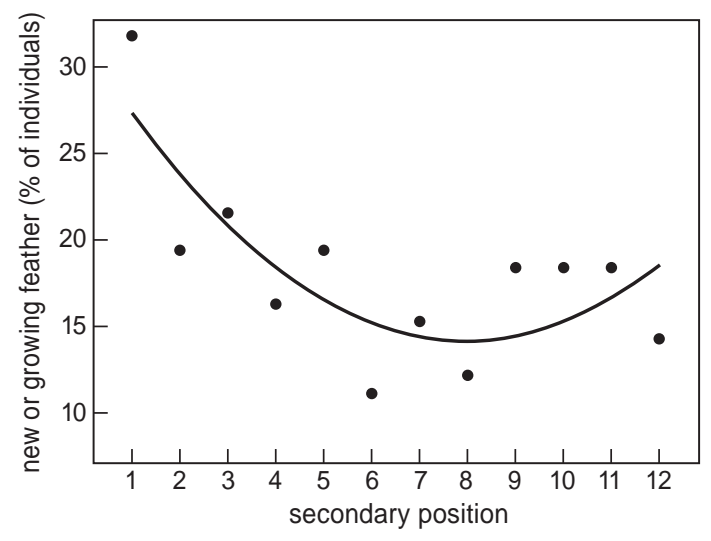

Figure 4. Percentage of birds with new or growing feathers in each considered secondary position. A quadratic regression line shows the underlying trend $\left(\mathrm{y}=0.3 \mathrm{x}^{2}\right.$ $\left.-4.3 \mathrm{x}+31.4, \mathrm{R}_{\text {adj }}^{2}=0.53, n=98\right)$.

for other waders (e.g. Dunlins Calidris alpina, Holmgren et al. 2001), our estimates compare well to the data reported in the literature, although published ranges are based on small numbers of birds. Contrary to what is reported in Cramp \& Simmons (1983) and Ginn \& Melville (1983), we did not record any evidence regarding suspended moult (sensu Ashmole 1962), nor serially descendant moult following moult suspension. Given that most available moult data come from northern populations (e.g. BTO moult cards, Ginn \& Melville 1983), it could be hypothesised that this moult strategy is more widespread in the northern part of the species' range, while at southern latitudes Stone-curlews could be favoured by a relatively long season of fair weather, which should guarantee enough time to complete the moult cycle. This hypothesis is supported by data from other waders, such as the Grey Plover Pluvialis squatarola, in which the frequency of birds with moult suspension is relatively high at higher latitudes (5-40\%; Serra et al. 2006 and references therein) and near zero in south-eastern India (Balachandran et al. 2000).

One of the remarkable features of the pattern of moult here described is the extensive overlap between breeding and moulting. Indeed, especially 
in temperate regions, birds tend to delay moult until breeding has (nearly) finished (Morton 1992, Hemborg 1999, Hemborg et al. 2001, Arroyo et al. 2004), in order to reduce the overlap between two energy-demanding activities (Jenni \& Winkler 1994, Moreno 2004 and references therein). European waders (families Haematopodidae, Recurvirostridae, Charadriidae, Scolopacidae) show various degrees of overlap between breeding and moult, but usually this overlap includes less than a quarter of the breeding period. The case of Stonecurlew here documented is noteworthy, because in our population (but see also Cramp and Simmons 1983) this overlap extends over most of the breeding season, excluding its very beginning. Primary moult is also quite slow ( $>5$ months) compared to other wader species, which usually complete their moult cycle in less than 4 months; longer moult cycles are usually associated with moult suspension. It could be hypothesized that this slow and constant rate facilitates the overlap between breeding and moult by spreading the costs of moult homogeneously over the whole period and by avoiding the detrimental effects on feather quality of rapid moult cycles (Dawson et al. 2000, Serra 2001). It is interesting to note that, while usually avoided in most temperate species, an extensive moult-breeding overlap is relatively common among tropical birds (Foster 1974, Moreno 2004), where it is associated with small clutches and long breeding seasons (Foster 1974).

We tested whether a prolonged breeding season correlates with an extended moult-breeding overlap using literature data of 41 Palearctic wader species (Appendix 1). Indeed, moult-breeding overlap was positively correlated only with the length of the breeding season, using both the raw data and phylogenetically independent contrasts (Table 4). Female body mass and clutch mass were related to each other, but not to moult-breeding overlap (Table 4). Foster (1974) proposed that the above-mentioned set of traits is a means by which tropical birds may maximise their breeding output in areas where nesting success is strongly dependent on renesting potential. According to this
Table 4. Correlations between the length of the breeding season (in months), clutch mass, female body mass and extent of primary moult-breeding overlap (in months) in Palaearctic waders. Upper diagonal part: Spearman rank partial correlation using species level data $(n=41)$. Lower diagonal part: Spearman rank partial correlation using phylogenetically independent contrasts $(n=40)$. See Appendix 1 for the species and data used.

\begin{tabular}{lcccc}
\hline & $\begin{array}{c}\text { Breeding } \\
\text { season }\end{array}$ & $\begin{array}{c}\text { Clutch } \\
\text { mass }\end{array}$ & $\begin{array}{c}\text { Female } \\
\text { body mass }\end{array}$ & Overlap \\
\hline Breeding season & - & -0.11 & 0.16 & $0.53^{* *}$ \\
Clutch mass & -0.22 & - & $0.71^{* *}$ & -0.06 \\
Female body mass & 0.22 & $0.70^{* *}$ & - & 0.20 \\
Overlap & $0.44^{*}$ & 0.08 & 0.21 & - \\
\hline
\end{tabular}

hypothesis, the high nest predation in the tropics (Ricklefs 1969) may select for the capacity to renest repeatedly both by reducing the investment in single clutches and by prolonging the breeding season, thus favouring moult-breeding overlap. It is difficult to determine if the observed correlation between moult-breeding overlap and length of the breeding season in Palearctic waders could be explained by considering the selective effect of predation rate on renesting potential. Indeed the available data do not take into consideration the significant variability among populations both regarding breeding phenology (e.g. Cramp \& Simmons 1983) and timing and duration of primary moult (e.g. Pienkowski et al. 1976, Underhill 2003). Moreover, it seems likely that other factors, such as ecological (e.g. latitude of breeding grounds, local climate, nutritional constraints) and physiological (e.g. activity of the immune system) constraints, should be taken into account (see also Moreno 2004). Testing these hypotheses is beyond the scope of this paper.

It should be noted, that among waders, the Stone-curlew represents a clear outlier, both considering the extent of the moult-breeding overlap (about $90 \%$ of the breeding season) and the strongly reduced parental investment in single clutches (c. 19\% of female body mass). Moreover, 
as expected for an open-nester (Lack 1968, Ricklefs 1969, Martin \& Li 1992, Bennett \& Owens 2002), nest survival of the Stone-curlew is relatively low (only 40-60\% of the nests produce at least one hatchling, Giunchi et al. unpubl. data), and this species has a very high potential for renesting (4 attempts per year, both considering replacement and second clutches, see also Vaughan \& Vaughan Jennings 2005). Females usually replace their lost clutches in less than 15 days (Nethersole-Thompson \& Nethersole-Thompson 1986; Giunchi et al. unpubl. data). This evidence is obviously only circumstantial, but the observed pattern is intriguing and surely deserves further investigation, possibly comparing data belonging to different populations of Stone-curlew.

Even though the moulting process began while birds were still breeding, most of secondary feathers were moulted during the post-breeding season. As observed for primaries, moult rate of secondaries was slow, and this could explain why apparently only some of these feathers were replaced on the breeding grounds. Indeed, the data at hand suggest that Stone-curlews shed secondaries before starting autumn migration and probably arrested this process at the end of primary moult (the last record of birds actively moulting secondary feathers was from the beginning of October). Even though we have no data regarding moult on the wintering grounds, moult suspension seems unlikely since we did not record any birds showing secondaries distinctly younger than the not yet moulted primaries. Interestingly, juveniles do not replace their secondary feathers until their second year of life, and thus they could be easily recognized as having homogeneous secondary feathers till late spring.

To our knowledge, this is the first time that partial moult of secondary feathers has been described in Stone-curlew, even though this feature is not uncommon among medium-large waders (see e.g. the Golden Plover Pluvialis apricaria, Cramp \& Simmons 1983) and may be selected for to spread the costs of moult over a long time period (see Herremans 2000 and references therein). In the Stone-curlew this strategy could be facilitated also by secondaries needing less quick replacement due to moderate abrasion (Giunchi et al. pers. observ.), given the limited rubbing against vegetation (our Stone-curlews inhabit open habitat), and the reduced sun exposition (in folded wing, secondaries are completely concealed by long tertials and scapulars). Secondary moult shows large between-individual variation both in the number of retained feathers, varying between 2 and 10 (median $6.5, n=24$ ), and in its sequence, although it tended to follow the pattern recorded for other waders (Prater et al. 1977). This between-individual variation may come about by timing differences, as birds starting moult earlier may have more time to complete the moult of both primaries and secondaries (note that the progress of secondary moult and the onset of primary moult were significantly correlated). Moreover some degree of complementary moult could not be excluded, because in only a few cases we were able to distinguish three generations among old secondaries. Unfortunately, we have too few data regarding the reproductive output of the observed birds to test if parental investment might constitute a severe constraint on wing moult, as otherwise observed for other species (e.g. Pietiaeinen et al. 1984, Hemborg \& Lundberg 1998). Clearly the resource allocation between current reproduction and moult in the Stonecurlew deserves further investigations.

\section{ACKNOWLEDGEMENTS}

We are grateful to all of the people which helped us in the field: S. Battilocchi, R. Carini, F. Carpita, L. Catellani, E. Chierici, E. Logozzo, S. Masi, F. Piccio, F. Pino, F. Sturlese, and M. Ventimiglia. We would like to thank also R. Rusticali, N. Baccetti and F. Zanichelli for their invaluable advice. We are also grateful to N. E. Baldaccini, D. Heg and an anonymous reviewer for their very helpful comments on earlier drafts of the manuscript. We appreciate the improvements in English usage made by Jim Armacost through the Association of Field Ornithologists' program of editorial assistance. 


\section{REFERENCES}

Arroyo B., Minguez E., Palomares L. \& Pinilla J. 2004. The timing and pattern of moult of flight feathers of European Storm Petrel Hydrobates pelagicus in Atlantic and Mediterranean breeding areas. Ardeola 51: 365-373.

Ashmole N.P. 1962. The Black Noddy Anous tenuirostris on Ascension Island. Part 1. General biology. Ibis 103b: 235-273.

Balachandran S., Hussain S.A. \& Underhill L.G. 2000. Primary moult, biometrics, mass and age composition of Grey Plovers Pluvialis squatarola in Southeastern India. Bird Study 47: 82-90.

Bennett P.M. \& Owens I.P.F. 2002. Evolutionary ecology of birds - Life histories, mating systems and extinction. Oxford University Press, Oxford.

Bowman A.W. \& Azzalini A. 1997. Applied smoothing techniques for data analysis: The kernel approach with S-Plus illustrations. Oxford University Press, Oxford.

Burnham K.P. \& Anderson D.R. 2002. Model selection and multimodel inference - A practical informationtheoretic approach, second edition. Springer-Verlag, New York.

Cramp S. \& Simmons K.E.L. 1983. The Birds of the Western Palearctic. Oxford University Press, London $\&$ New York.

Dawson A. 2005. The scaling of primary flight feather length and mass in relation to wing shape, function and habitat. Ibis 147: 283-292.

Dawson A., Hinsley S.A., Ferns P.N., Bonser R.H.C. \& Eccleston L. 2000. Rate of moult affects feather quality: a mechanism linking current reproductive effort to future survival. Proc. R. Soc. Lond. B. 267: 2093-2098.

del Hoyo J., Elliott A. \& Sargatal J. 1996. Handbook of the Birds of the World. Vol. 3: Hoatzin to Auks. Lynx editions, Barcelona.

Felsenstein J. 1985. Phylogenies and the comparative method. Am. Nat. 125: 1-15.

Foster M.S. 1974. A model to explain molt-breeding overlap and clutch size in some tropical birds. Evolution 28: 182-190.

Ginn H.B. \& Melville D.S. 1983. Moult in Birds. BTO Guide 19. BTO, The Nunnery.

Hemborg C. 1999. Annual variation in the timing of breeding and moulting in male and female Pied Flycatchers Ficedula hypoleuca. Ibis 141: 226-232.

Hemborg C., Sanz J.J. \& Lundberg A. 2001. Effects of latitude on the trade-off between reproduction and moult: a long-term study with pied flycatcher. Oecologia 129: 206-212.

Hemborg C. \& Lundberg A. 1998. Costs of overlapping reproduction and moult in passerine birds: an experiment with the pied flycatcher. Behav. Ecol. Sociobiol. 43: 19-23.

Herremans M. 2000. The 'chaotic' flight feather moult of the Steppe Buzzard Buteo buteo vulpinus. Bird Study 47: 332-343.

Holmgren N.M.A., Jonsson P.E. \& Wennerberg L. 2001. Geographical variation in the timing of breeding and moult in Dunlin Calidris alpina on the Palearctic tundra. Polar Biol. 24: 369-377.

Jenni L. \& Winkler R. 1994. Moult and ageing of European passerines. Academic Press, London.

Lack D. 1968. Ecological Adaptations for breeding in birds. Methuen, London.

Martin T.E. \& Li P.J. 1992. Life-history traits of open-nesting vs cavity-nesting birds. Ecology 73: 579-592.

Moreno J. 2004. Moult-breeding overlap and fecundity limitation in tropical birds: a link with immunity? Ardeola 51: 471-476.

Morton M.L. 1992. Control of postnuptial molt in the mountain White-crowned Sparrow - a perspective from field data. Ornis Scand. 23: 322-327.

Nethersole-Thompson D. \& Nethersole-Thompson M. 1986. Waders. Their breeding, haunts and watchers. T. \& A.D. Poyser, Calton.

Newton I. \& Rothery P. 2005. The timing, duration and pattern of moult and its relationship to breeding in a population of the European Greenfinch Carduelis chloris. Ibis 147: 667-679.

Paradis E., Claude J. \& Strimmer K. 2004. APE: Analyses of phylogenetics and evolution in $\mathrm{R}$ language. Bioinformatics 20: 289-290.

Pienkowski M.W., Knight P.J., Stanyard D.J. \& Argyle F.B. 1976. The primary moult of waders on the Atlantic coast of Morocco. Ibis 118: 347-365.

Pietiaeinen H., Saurola P. \& Kolunen H. 1984. The reproductive constraints on moult in the Ural Owl Strix uralensis. Ann. Zool. Fenn. 21: 277-281.

Pollonara E., Giunchi D., Zanichelli F. \& Baldaccini N.E. 2001. Data on the consistency of the population of Stone-curlew (Burhinus oedicnemus) breeding in the Taro Regional Park. Avocetta 25: 236. (in Italian)

Prater A.J., Marchant J.H. \& Vuorinen J. 1977. Guide to the identification and ageing of Holarctic waders. BTO, Tring.

R Development Core Team 2007. R: a language and environment for statistical computing. R Foundation for Statistical Computing, Vienna. 
Ricklefs R. E. 1969. An analysis of nesting mortality in birds. Smithson. Contrib. Zool. 9: 1-48.

Serra L., Clark N.A. \& Clark J.A. 2006. Primary moult, body mass and migration of Grey Plovers Pluvialis squatarola in Britain. Ibis 148: 292-301.

Serra L. 2001. Duration of primary moult affects primary quality in Grey Plovers Pluvialis squatarola. J. Avian Biol. 32: 377-380.

Sokal R.R. \& Rohlf F.J. 1995. Biometry, third edition. W.H. Freeman and Company, New York.

Summers R.W., Underhill L.G., Nicoll M., Strann K.B. \& Nilsen S.O. 2004. Timing and duration of moult in three populations of Purple Sandpipers Calidris maritima with different moult/migration patterns. Ibis 146: 394-403.

Thomas G.H., Wills M.A. \& Szekely T. 2004. A supertree approach to shorebird phylogeny. BMC Evol. Biol. 4: 28-28.

Underhill L.G. 2003. Within ten feathers: Primary moult strategies of migratory waders (Charadrii). In: Berthold P., Gwinner E. \& Sonnenschein E. (eds) Avian migration. Springer-Verlag, Berlin, pp. 187-197.

Underhill L.G. \& Zucchini W. 1988. A model for avian primary moult. Ibis 130: 358-372.

Underhill L.G., Zucchini W. \& Summers R.W. 1990. A model for avian primary moult-data types based on migration strategies and an example using Redshank Tringa totanus. Ibis 132: 118-123.

Vaughan R. \& Vaughan Jennings N. 2005. The Stone Curlew Burhinus oedicnemus. Isabelline Book, Falmouth.

\section{SAMENVATTING}

In het Regionale Park Taro (ten westen van Parma, Italië) komt de Griel Burhinus oedicnemus talrijk voor. In de zomers van 1998-2007 werden er 141 vogels gevangen om het ruistadium van de vleugelpennen vast te stellen. De rui van de handpennen begon begin mei en eindigde pas in oktober, daarmee een groot deel van de broedtijd overlappend. De rui van de handpennen verliep volgens een vast patroon, de vervanging van de armpennen was veel onregelmatiger. Bovendien werd binnen een zelfde seizoen slechts een deel van de armpennen geruid, waarbij vooral de middelste pennen werden overgeslagen. Vogels hadden daarom armpennen van verschillende leeftijd. Omdat jonge vogels hun armpennen pas na de eerste winter begonnen te vervangen, bood dit de mogelijkheid vogels in hun tweede kalenderjaar van oudere vogels te onderscheiden. Gelijktijdig ruien en broeden, zoals Grielen doen, is betrekkelijk ongewoon onder steltlopers. Door de rui over een lange periode uit te smeren kunnen de energetische kosten per tijdseenheid mogelijk verlaagd worden. Dit zou een aanpassing kunnen zijn om binnen een zelfde seizoen enkele broedpogingen te doen. Steun voor deze veronderstelling komt uit een vergelijking tussen 41 steltlopersoorten: hoe langer het broedseizoen duurt, des te groter is de overlap van rui van de handpennen en broedactiviteiten.

(DH)

Corresponding editor: Dik Heg

Received 18 April 2008; accepted 2 September 2008 
Appendix 1. Palaearctic waders considered in the analysis $(n=41)$ belonging to seven families (del Hoyo et al. 1996). Variables were derived from Cramp \& Simmons (1983): (1) length of the breeding season (accuracy by 0.5 months): period of egg laying and caring for young, excluding outliers (early eggs and late broods); (2) modal clutch mass (by $1 \mathrm{~g}$ ); (3) modal female body mass (by $1 \mathrm{~g}$ ); (4) extent of the overlap (by 0.5 months) between primary moult and the breeding season (excluding outlying data for the onset and termination of primary moult). Analyses were performed by means of the Spearman rank partial correlation both using species level data and phylogenetically independent contrasts (Felsenstein 1985). These contrasts were calculated by considering the phylogenetic tree reported in Thomas et al. (2004), randomly resolving all multichotomies. Analyses were performed using the R-package APE 2.0-2 (Paradis et al. 2004).

\begin{tabular}{|c|c|c|c|c|c|}
\hline Species & Family & $\begin{array}{l}\text { Breeding } \\
\text { season } \\
\text { (months) }\end{array}$ & $\begin{array}{l}\text { Clutch } \\
\text { mass } \\
(\mathrm{g})\end{array}$ & $\begin{array}{l}\text { Female } \\
\text { body mass } \\
(\mathrm{g})\end{array}$ & $\begin{array}{c}\text { Moult-breeding } \\
\text { overlap } \\
\text { (months) }\end{array}$ \\
\hline Burhinus oedicnemus & Burhinidae & 5 & 84 & 449 & 4.5 \\
\hline Haematopus ostralegus & Haematopodidae & 4.5 & 140 & 616 & 2.5 \\
\hline Himantopus himantopus & Recurvirostridae & 3 & 88 & 180 & 0.5 \\
\hline Recurvirostra avosetta & Recurvirostridae & 4 & 129 & 325 & 1 \\
\hline Vanellus spinosus & Charadriidae & 5 & 64 & 148 & 3 \\
\hline Vanellus vanellus & Charadriidae & 5 & 100 & 217 & 3 \\
\hline Charadrius hiaticula & Charadriidae & 5 & 46 & 65 & 2 \\
\hline Charadrius dubius & Charadriidae & 5 & 31 & 39 & 2 \\
\hline Charadrius alexandrinus & Charadriidae & 4 & 27 & 60 & 1.5 \\
\hline Eudromias morinellus & Charadriidae & 3.5 & 48 & 116 & 1.5 \\
\hline Pluvialis apricaria & Charadriidae & 3.5 & 139 & 191 & 3 \\
\hline Pluvialis squatarola & Charadriidae & 3 & 140 & 220 & 0.5 \\
\hline Cursorius cursor & Glareolidae & 4.5 & 28 & 128 & 0 \\
\hline Glareola nordmanni & Glareolidae & 2.5 & 44 & 96 & 0 \\
\hline Glareola pratincola & Glareolidae & 3.5 & 30 & 74 & 1 \\
\hline Dromas ardeola & Dromadidae & 4.5 & 45 & 325 & 3 \\
\hline Numenius arquata & Scolopacidae & 3.5 & 300 & 788 & 1 \\
\hline Numenius phaeopus & Scolopacidae & 3 & 200 & 398 & 0 \\
\hline Limosa lapponica & Scolopacidae & 2.5 & 148 & 273 & 1 \\
\hline Limosa limosa & Scolopacidae & 3.5 & 162 & 315 & 1.5 \\
\hline Scolopax rusticola & Scolopacidae & 5 & 100 & 320 & 1.5 \\
\hline Gallinago media & Scolopacidae & 3.5 & 82 & 190 & 1.5 \\
\hline Gallinago gallinago & Scolopacidae & 4.5 & 68 & 112 & 1 \\
\hline Lymnocryptes minimus & Scolopacidae & 3 & 56 & 68 & 2 \\
\hline Tringa hypoleucos & Scolopacidae & 3.5 & 48 & 50 & 0 \\
\hline Arenaria interpres & Scolopacidae & 2 & 72 & 115 & 0 \\
\hline Limicola falcinellus & Scolopacidae & 2.5 & 36 & 39 & 0 \\
\hline Philomachus pugnax & Scolopacidae & 3 & 88 & 118 & 1 \\
\hline Calidris minuta & Scolopacidae & 2.5 & 25 & 31 & 0 \\
\hline Calidris alpina & Scolopacidae & 2.5 & 40 & 55 & 0 \\
\hline Calidris maritima & Scolopacidae & 2 & 52 & 70 & 0 \\
\hline Calidris temminckii & Scolopacidae & 2.5 & 24 & 28 & 0 \\
\hline Phalaropus fulicaria & Scolopacidae & 2 & 31 & 61 & 0.5 \\
\hline Phalaropus lobatus & Scolopacidae & 2.5 & 25 & 35 & 0 \\
\hline Tringa glareola & Scolopacidae & 3 & 56 & 60 & 0 \\
\hline Tringa erythropus & Scolopacidae & 3 & 98 & 157 & 2 \\
\hline Tringa totanus & Scolopacidae & 4 & 89 & 135 & 1 \\
\hline Tringa nebularia & Scolopacidae & 3.5 & 145 & 200 & 0.5 \\
\hline Tringa stagnatilis & Scolopacidae & 3.5 & 56 & 76 & 0 \\
\hline Tringa ochropus & Scolopacidae & 3 & 62 & 85 & 1 \\
\hline Tringa cinerea & Scolopacidae & 2.5 & 52 & 75 & 0 \\
\hline
\end{tabular}

